\title{
The Application of Artificial Intelligence in Project Management Research: A Review
}

\author{
Jesús Gil Ruiz ${ }^{1 *}$, Javier Martínez Torres², Rubén González Crespo ${ }^{3}$ \\ ${ }^{1}$ School of Doctorate Programs, Universidad Internacional de La Rioja, Logroño, La Rioja (Spain) \\ ${ }^{2}$ Department of Applied Mathematics I, Universidad de Vigo, Vigo (Spain) \\ ${ }^{3}$ School of Engineering and Technology, Universidad Internacional de La Rioja, Logroño, La Rioja \\ (Spain)
}

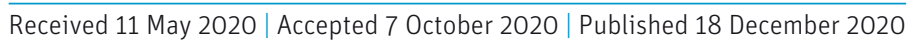

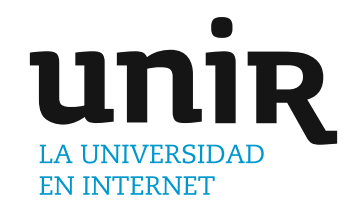

KEYWORDS

Artificial Intelligence, Decision Support Systems, Evolutionary Diffuse Hybrid Neuronal Network, Project Management, Project Success, Critical.

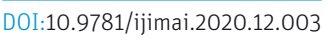

\section{INTRODUCTION}

$\mathrm{N}$ recent decades, projects have tended to increase in complexity to the point where they have become mega projects such as, for example, the particle accelerator (CERN) or the photovoltaic plants (BEN BAN solar) with the power of almost two nuclear reactors (1.8 $\mathrm{GW}$ ). Meanwhile, the attendant industrial growth has resulted in a greater degree of competence when addressing these projects in terms of their control and development, which has become a necessity since the projects often involve extremely tight profit margins. Adopting certain project management methodologies (e.g., PMI, [130], IPMA, and PRINCE) allows us to manage the start and the evolution of a project in the most optimal way possible, controlling and responding to any problems that arise during the project, facilitating their completion and approval before any further risks arise. However, these methodologies are arguably not sufficient since the processes must be clearly structured with complete and clear control of the project in all the relevant areas. The aim must be to improve the experience of the project manager when dealing with the various adverse situations that will likely be encountered in the development of the project while simultaneously preventing errors due to a lack of planning or management, such as in portfolio management [41]. While the desired project management methodology (PMP) practices are currently being implemented - which allow for the best possible management of a project - as noted above, the processes must be clearly structured

* Corresponding author.

E-mail address: jesus.gil@unir.net
[142] and all areas of the project must be tightly controlled, including in terms of the information systems [66].

In fact, the current methodologies are largely insufficient since the project manager is generally left to deal with the decision making, who, based on his or her professional experience, must make "intuitive" decisions based on previous cases when facing a problem with infinite variables and possibilities. Here, it is virtually impossible to face all the issues and challenges that today's projects entail. In fact, there are a number of diverse reasons why projects tend to fail. However, after more than ten years working on projects and learning about other professionals' experiences, we would highlight the following:

- Unassembled objectives or objectives that are not clearly defined.

- There is no communication protocol.

- Lack of definition of roles and responsibilities.

- Expectation management.

- Scope Corruption.

- Ignore Project Risks.

- Lack of involvement of participants.

- Absence of formal planning.

- Estimated errors / unrealistic.

- Absence of methodologies, templates and documentation.

- Lack of resources.

- Absence of evidence or little focus on quality.

- Little formalized modification process.

- Lack of training.

- Little or no address support. 
While all these points can be improved with a clear PMP, they will always depend on the human factor, and many of them are difficult to deal with, even for an experienced project manager. In view of this, artificial intelligence (AI) can play an important role in a variety of areas.
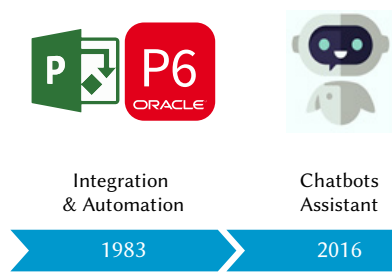

Chatbots Assistant

2016

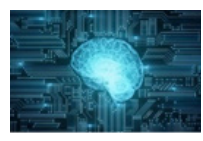

Machine Learning-

Bases Project Management

2023-2035

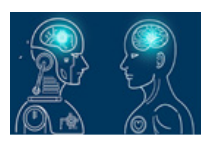

Autonomus Artificial Intelligence Project Management
Fig. 1.Evolution of AI in project management [100].

Fig. 1 shows the evolution that has taken place in the last 37 years, and what is expected in the future.

\section{Integration, Automation, and Chatbot Assistants}

The first phase involved the integration of task automation software such as Microsoft Project and Primavera (Oracle), which first appeared in 1983. In recent years, chatbot assistants are being used for meetings and management equipment recaps and reminders, etc. While in everyday life, we have been surrounded by chatbots for several years, the area is still in its infancy in the world of project management.

\section{Project Management Based on Machine Learning}

The third stage began with the purest concept of AI. In the area of project management, machine learning [132] has been implemented to allow for predictive and corrective analysis aimed at providing the project manager with data for decision making in terms of, for example, how to plan and manage project resources within certain parameters and restrictions or how to deal with problems and risks in order to achieve project success based on the history of past projects. In less than ten years, AI could work with the lessons learned from the project history and could suggest new project schedules, adapting [87] to the real time according to the performance of the resources and the progress of the project. An AI system could even alert the project manager about any possible risks and opportunities through the use of real-time project data analysis. A new vision will be created when it comes to directing projects by minimizing the risks involved in decision making. An AI system may be capable of making decisions for itself, which will herald the new era of AI [19], one that will mark the fourth phase of the evolution of project management.

The objective of this work is to review the new proposals emerging in the field of $\mathrm{AI}$ in the various areas, and to ascertain which techniques could be the most effective for ensuring the success of the projects. We also look at all the applications and uses [112] of $\mathrm{AI}$ in the broad field of project management, from the commercial development phase to the construction and commissioning phase, including its application in the areas of operation and maintenance. Numerous international studies have recently emerged in relation to optimization techniques such as neural networks [27], support vector machines [8], evolutionary algorithms [61], and hybrid systems [32] [2]. Given their relevance to PMP, these techniques will improve the experience of the project manager when facing the various adverse situations that will be encountered in the development of the project, and will help to prevent the errors resulting from a lack of planning or management.

\section{Summary of Machine Learning Techniques}

A project has traditionally been classified as successful if it has complied with the following restrictions: scope, budget, and schedule.
The objective of this document is to review the new proposals related to AI to improve the success of the project and to ascertain the applications and uses that AI has in the broad field of project management, from the development phase of the business [91] to its start-up [154] and onto its operation [125] [165] and maintenance [95] [106] [156].

\section{A. Individual Techniques}

We begin by outlining each of the techniques used in the field of project management.

\section{Artificial Neural Networks (ANN)}

Neural networks attempt to simulate [162] the way the human brain works as closely as possible, and are currently used in a number of fields, including medicine, engineering, and construction management [120]. The neural network conforms to data patterns and offers better results. This is achieved through learning the network [165] and comparing the results of the neural network with the data of other projects until the performance of the neural network is optimized.

Neural networks have the following advantages [109]:

- The storage of information throughout the network.

- The ability to work with incomplete knowledge.

- Fault tolerance.

- The ability to carry out machine learning.

- A parallel-processing capacity.

These advantages make its implementation in computational models highly interesting in all fields of research, text analytics [119], and project management [76].

\section{Neural Networks of High Order (HONNS)}

HONNs were originally proposed in the 1960 s to perform nonlinear discrimination but were discarded due to the enormous amount of higher-order terms [43]. Beginning in the mid-1990s, several researchers relied on HONNs rather than ONNs to resolve specific classification problems [79]. In a high-order neuronal, the neuron outputs are fed back to the same neuron or to neurons in the previous layers, as shown in Fig. 2. The signals are transmitted in forward and backward directions. High-order artificial neural networks are mainly based on the Hopfield model.

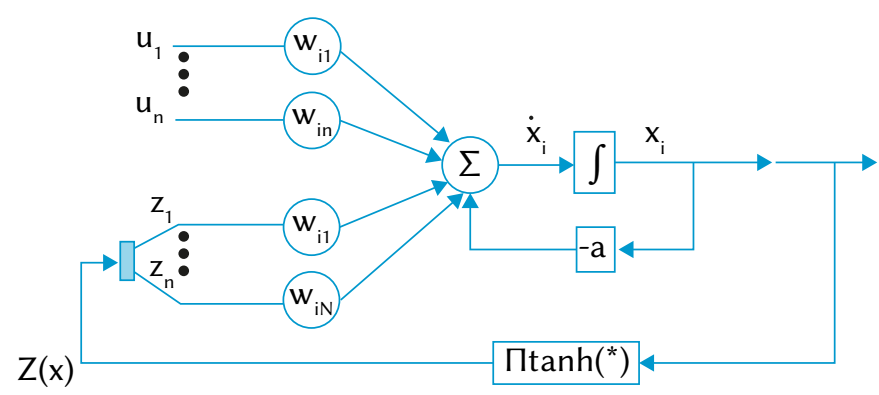

Fig. 2. Neural Network of high order [135].

\section{Hopfield Neural Network (HNN)}

The HNN [146] is a form of high-order artificial neural network with a single layer of fully connected neurons (i.e., all neurons are also connected to each other, as shown in Fig. 3) and provides a method to resolve combinatorial optimization problems. A HNN is guaranteed to converge to a local minimum if a problem can be described as an energy function with a minimum corresponding to the optimal solution [60] [122]. 


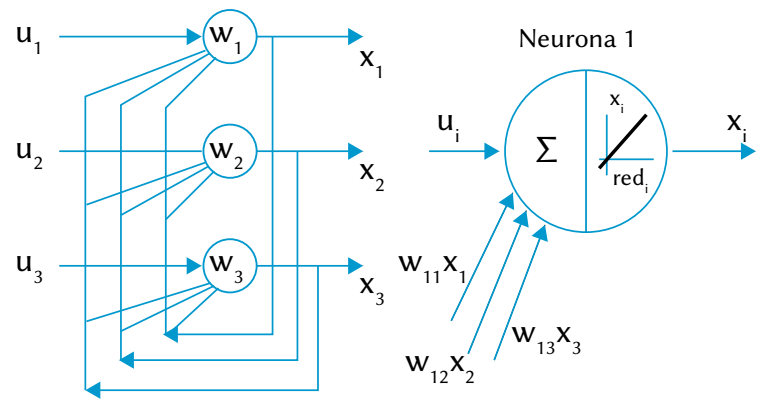

Fig. 3. Topology of Hopfield networks, here with 3 neurons as an example [102].

\section{Fuzzy Logic (FL)}

FL was initially proposed as a tool to describe uncertainty and inaccuracy [163]. Since it mimics the higher-order mode in which the human brain makes decisions in the face of uncertainty or vagueness, FL provides an effective way for automated systems to describe highly complex [48], poorly defined, or difficult to analyze subjects. In general, FL is composed of a fuzzifier, a rule base, an inference engine, and a defuzzifier [145] as shown in Fig. 4. The FL approach involves a number of issues that have yet to be overcome [57], such as the configuration of the membership function, the determination of the composition operator, and the acquisition of fuzzy rules that are specific [152] to the application. While FL parameters can be determined using the experience and knowledge of experts, determining these parameters in the absence of such experts remains difficult, especially in terms of complex issues.

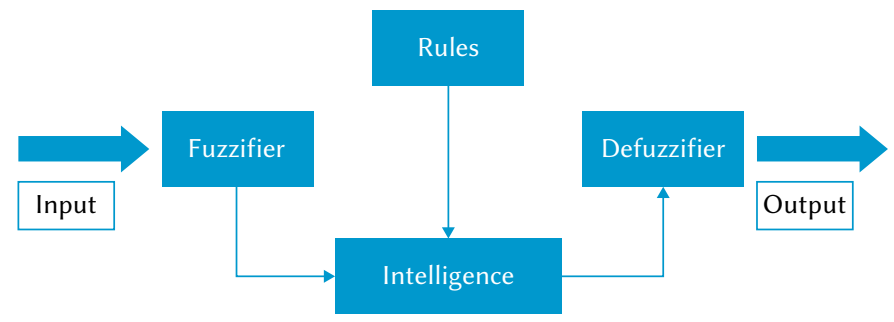

Fig. 4. Architecture of fuzzy logic systems [153].

\section{Fuzzy Cognitive Maps (DCMs)}

DCMs present an extension of cognitive maps and constitute a fuzzy graphical structure (as shown in Fig. 5) used to represent causal reasoning [96]. Their application is recommended for domains where the concepts and relationships are fundamentally fuzzy, such as politics, history, and strategic planning (projects) [51]. In the diagram shown in Fig. 5, each node represents a fuzzy set or an event that occurs to some degree. Here, it should be clarified that nodes are causal concepts and can model events, actions, values, objectives, or processes. Using this technique also provides the benefits of visual modelling, simulation, and prediction. Scenario analysis contributes to the identification of different alternatives to reach a future state [124]. This presents a flexible strategic planning method that is frequently used in technology management. While DCMs have been used for scenario analysis, there is a lack of methodologies and tools that allow for a fully effective quantitative analysis of the generated scenarios. In the area of information technology management [104], the simulation of software development projects and risk analysis in ERP maintenance stand out. While the use of DCMs has been proposed for the integration of strategic planning in relation to information systems and processes [136], the possible project options are neither represented nor analyzed. Furthermore, despite the DCM applications for the selection of information technology projects, the technique has not been linked to the organizational models that are obtained by describing the business architecture through business modelling activities.

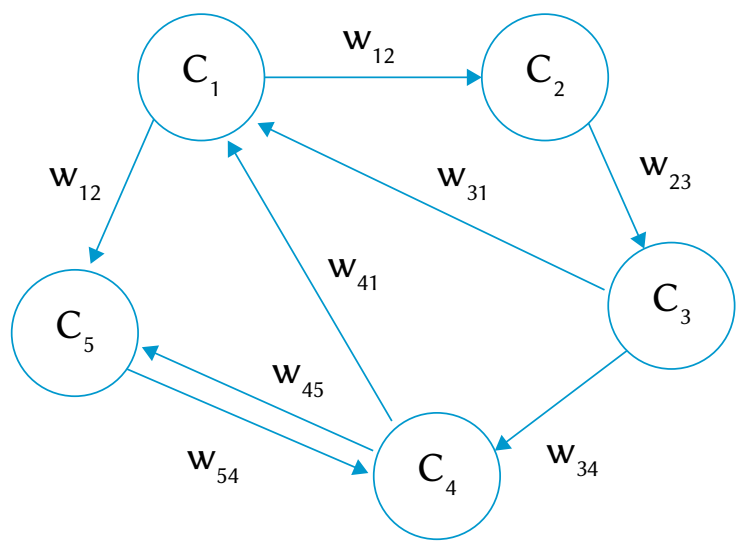

Fig. 5. Diffuse cognitive map topology [143].

\section{Genetic Algorithms (GAs)}

GAs present adaptive methods that can be used to resolve search and optimization problems and are based on the genetic process of living organisms. Over the generations, populations evolve in nature according to the principles of natural selection and the survival of the fittest, as postulated by Darwin (1859). The power of GAs lies in the fact that they present a robust technique and can successfully handle a wide variety of problems in different areas, including those where other methods encounter difficulties. While a GA is not guaranteed to find the optimal solution for a specific problem, empirical evidence suggests that solutions of an acceptable level can be identified in a timely manner when compared with other combinatorial optimization algorithms. The wide application of GAs is related to the problems for which there are no specialized techniques. In fact, these algorithms are used in countless applications, including in the fields of engineering [13], planning, games, and image processing [97]. Fig. 6 shows the working architecture of GAs.

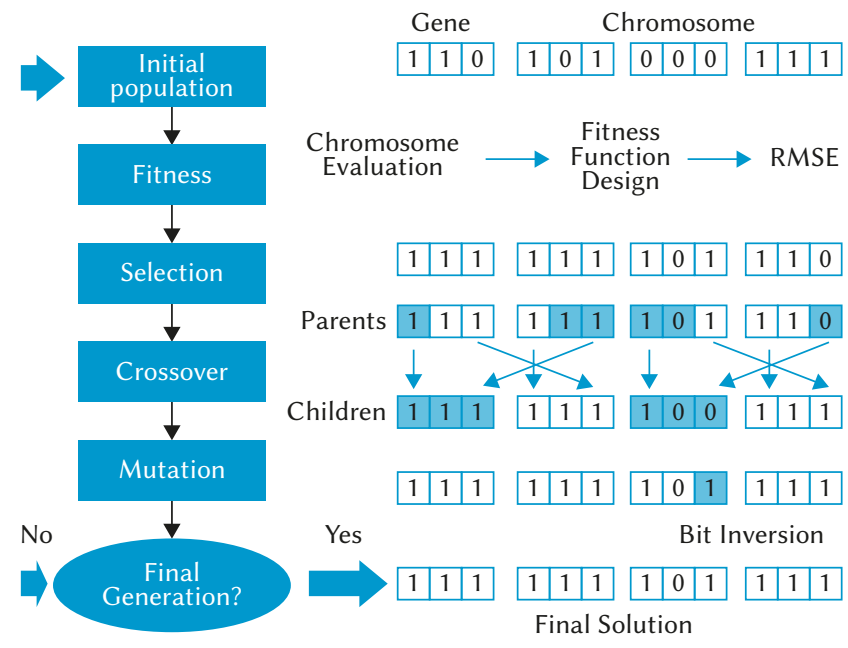

Fig. 6. Genetic Algorithms Diagram [70].

In general, the application of GAs to the planning of multiple projects that are to be executed simultaneously has yielded good results. In certain studies, a method based on penalties has been adopted [58] since it is difficult to obtain wholly correct solutions due to the complexity of the problem of optimization. While the identified solutions have, on the whole, been good, it is important to highlight 
that, in some cases, the solutions lay outside of the algorithms, since the best solutions do not always meet all the restrictions of the problem.

\section{Fast-Messy Genetic Algorithm (FmGA)}

The fmGA [64] can efficiently identify optimal solutions to problems with a large number of permutations. This type of algorithm is known for its flexibility due to its capacity for being combined with other methodologies to obtain better results [160]. The difference between this and other genetic algorithms is based on the possibility of modifying building blocks [86] to identify the best partial solutions, which help us to focus on a faster global solution [65]. Fig. 7 shows the working architecture of Messy GA.

Messy GA

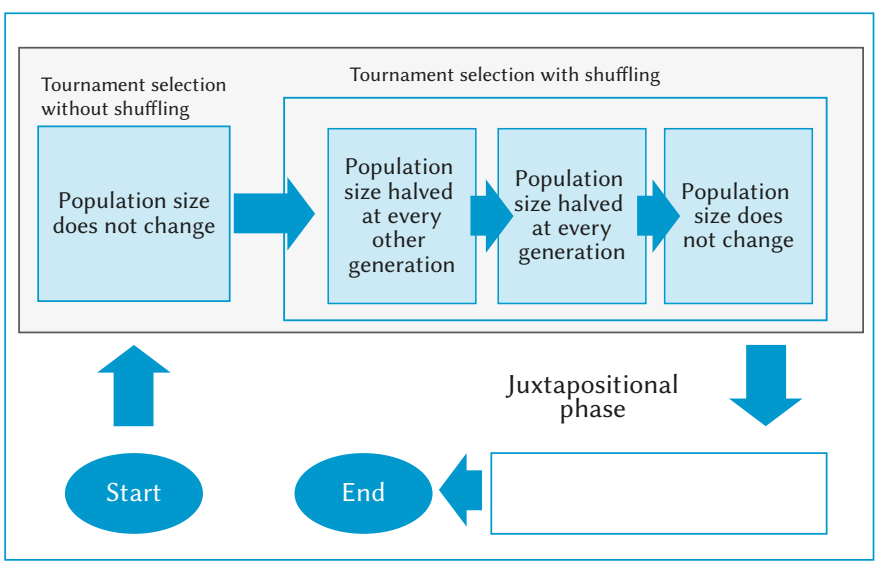

Fig. 7. Messy GA Architecture [99].

The algorithm is used in many applications, especially in relation to the resource management area of project management and civil engineering [45].

\section{Support Vector Machine (SVM)}

SVM presents a new form of learning, one that is more powerful than that using traditional learning tools. The technique can also be used to resolve data regression and categorization problems. Much like neural networks, SVM requires training and testing using a training dataset. The SVM functions allow for the better handling of unknown data and the technique generally has certain advantages over neural networks, often successfully applied to cost [10] and project management [158]. Within the area of classification, SVM belongs to the category of linear classifiers since it induces linear or hyperplane separators (as shown in Fig. 8), either in the original space of the input examples [20] either separable or quasi-separable (noise) - or in a transformed space (characteristic space).

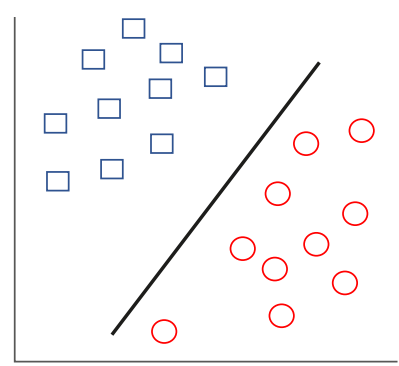

(a)

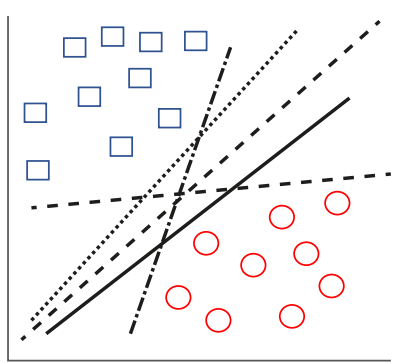

(b)
Fig. 8. Separation hyperplanes in a two-dimensional space of a set of separable examples from two classes: (a) example of separation hyperplane, (b) other examples of separation hyperplanes among the possible infinities [18].

\section{Bootstrap Technique (BT)}

The bootstrap method is a statistical technique used to estimate quantities across a specific population by averaging estimates from multiple small data samples [50]. Importantly, the samples are constructed by drawing observations from a large data sample one at a time before returning them to the data sample after they have been chosen. This allows a given observation to be included in a small sample more than once. This sampling approach is known as "replacement sampling." The bootstrap method can be used to estimate the size of a given population. This is achieved by repeatedly taking small samples, calculating the statistics, and then extracting the average. The bootstrap technique is a widely applicable and extremely powerful [159] statistical tool that can be used to quantify the uncertainty associated with a given estimator or statistical learning method (e.g., ascertaining the probability that a project will be successful). This is achieved by training the model with a sample and evaluating the capacity of the model in relation to the samples not included in the main sample. A useful feature of the bootstrap method [17] is that the sample resulting from the estimates often forms a Gaussian distribution. This technique is used in a wide variety of sectors, including the fields of medicine, financial management [154] [111][142], and project management [68]. An example for risk analysis is shown in Fig. 9.

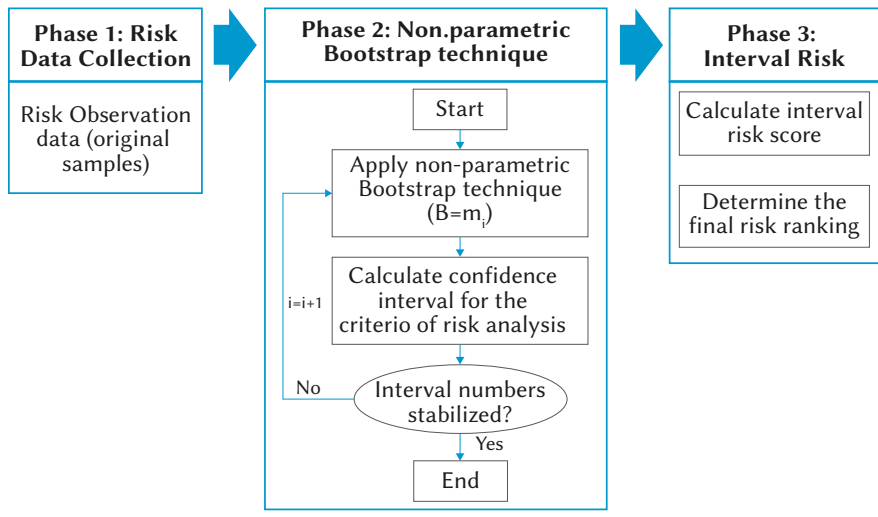

Fig. 9. Proposed approach for risk analysis [67].

\section{K-Grouping Means}

K-means presents an easy approach to creating groups of data from random datasets [84]. K-means grouping that incorporates heuristics such as Lloyd's algorithm is easy to implement, even in terms of large datasets, and has thus been widely used in many areas, such as market segmentation, computer vision, geostatistics, astronomy, and data mining in agriculture. The method is also used for the pre-processing in other algorithms, including in terms of identifying an initial configuration. While the main problem is that it cannot guarantee optimal convergence, it remains widely used due to its simplicity. Many algorithms can identify specific domains. K-means generally converges in practical applications [55], especially in pattern recognition problems. K-means clustering is also widely and commonly used due to its simplicity, while it does have certain inherent drawbacks, including having a fixed configuration for the optimal solution and being fairly time consuming.

\section{Other Relevant Optimization Techniques}

In the broad area of AI techniques, a number of well-known techniques are used, including the artificial bee colony algorithm [5], particle swarm optimization (PSO), and differential evolution (DE) [81]. There also exist various simple [128] or multi-objective Bayesian optimization algorithms [101]. 


\section{B. Hybrid Techniques}

Here, we describe each of the hybrid techniques used in project management. These hybrid systems are the future of AI and automated project management.

\section{Neuro-Fuzzy (FNN)}

The various logic and neural networks have special computational properties [4] that make them suitable for certain cases. For example, while neural networks offer advantages such as learning, adaptation, fault tolerance, parallelism, and generalization, they are not good at explaining how they have reached their decisions. In contrast, fuzzy systems - which reason using inaccurate information through an inference mechanism under linguistic uncertainty - are good at explaining their decisions but cannot automatically acquire the rules they use to make them. Meanwhile, neuro-diffuse systems [53] combine the learning capacity of RNAs with the linguistic interpretation power of diffuse inference systems. They are used in a multitude of applications and fields [137] [85], including mechanical engineering [155], image processing [74], electrical and electronic systems [129], forecasting and prediction [49], and risk identification in project management.

\section{Neural-Network-Adding Bootstrap}

A bootstrap that adds neural networks presents a combination of multiple artificial neural network classifiers [151]. This method uses more than one ANN-based classifier, meaning the final decision is made from each classifier through a voting system. The model output is obtained as a linear combination of the experts' output and the combined weights are calculated based on the input. Bierman proposed a new method to aggregate multiple models using boot replicas of training data, which is known as "packaging". It has been shown that the generalizability of the model can be significantly improved through this approach. The "bagging" idea is used to build robust neural network models, or BAGNET models.

Rather than select a single neural network model, a BAGNET model combines several neural network models to improve the precision and robustness, as shown in Fig. 10. The overall output of a BAGNET model presents a weighted combination of the outputs of individual neural networks. This approach has demonstrated a comparatively good performance.

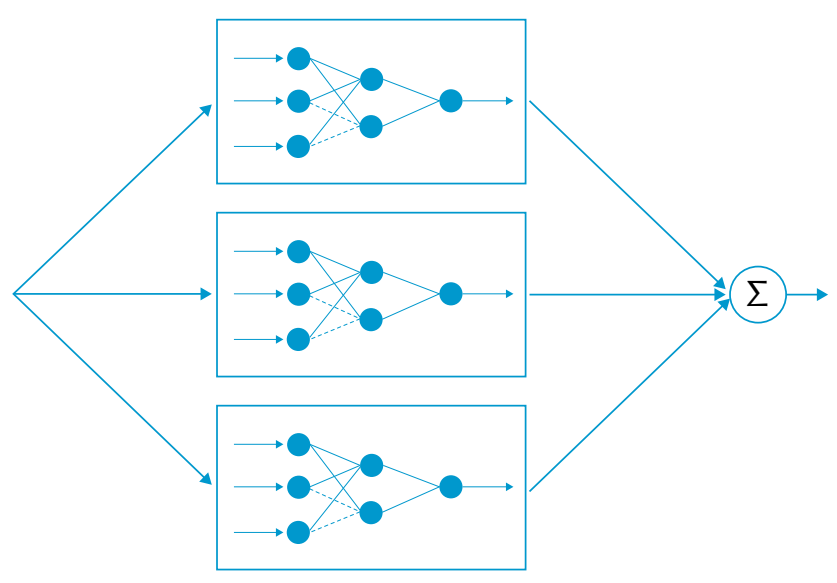

Fig. 10. Bagnet diagram [166].

\section{Neural Networks of Adaptive Reinforcement}

The main difference between this method and the above method is that adaptive reinforcement neural networks [147] use weights that are readjusted in each iteration, affording less importance to the solutions that have not been correctly classified. As a result, the classifiers focus on more complex samples to obtain an increasingly faster solution. A number of interesting studies on this technique are currently available [126] [103].

\section{Fuzzy Rule-Based Systems (FRBS) and Genetic Fuzzy Systems (GFS)}

FRBSspresent an extension of classical rule-based systems (hybrid systems, as shown in Fig. 11) [75] given that they deal with "IF-THEN" rules, the antecedents and consequents of which are made up of fuzzy logical statements, rather than classical ones. They have demonstrated their capacity for modelling, classification, and data mining problems in a large number of applications, which makes them highly useful for project management and control. A GFS is essentially a fuzzy system driven by a learning process based on evolutionary algorithms, which includes FL + GA, genetic programming, and evolution strategies, among other evolutionary algorithms [42].

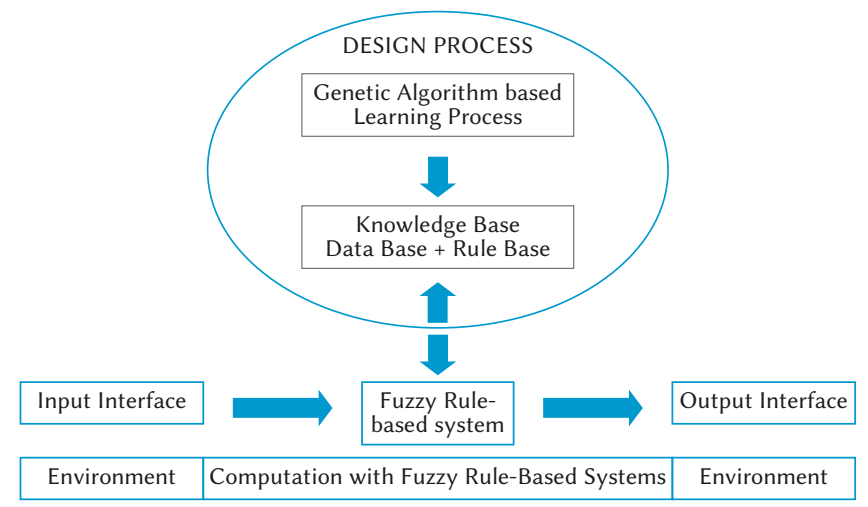

Fig. 11. FRBS Structure [71].

The central aspect of using a GA [40] for the machine learning of an FRBS is that the process can be analyzed as an optimization problem. This technique is frequently used in weather forecasts [46], the forecasting of renewable energy resources [144] (solar [90], wind [108]), military projects [52], and project management [12].

\section{Evolutionary Fuzzy Support Vector Machines Inference Model (EFSIM).}

The inference model of evolutionary diffuse support vector machines (EFSIM) presents a hybrid technique [35] that incorporates three different AI techniques: FL, SVM, and fmGA, as shown in Fig. 12. In this hybrid system, the FL deals with any vagueness and approximate reasoning, the SVM acts as a supervisory learning tool to handle diffuse input-output mapping, and the fmGA functions to optimize the FL and SVM parameters. Interesting research on this technique has been conducted in relation to project management [33].

\section{Evolutionary Fuzzy Neural Inference Model (EFNIM)}

EFNIM presents a resolution technique for hybrid systems [27] (composed of GA, FL, and NN, as shown in Fig. 13) that is used to resolve all types of problems. The complementary combination of its three elements maximizes the positive merits of each and helps to compensate for their inherent individual weaknesses. The GA is used for global optimization, the FL deals with uncertainties and handles approximate inferences, and the $\mathrm{NN}$ is used in the input-output mapping. Traditionally, the system has been used to resolve civil engineering problems [30] and presents a hybrid system that has great potential for assisting managers in implementing efficient long-term strategies and in taking the correct action for achieving the ultimate success of the project [94]. 


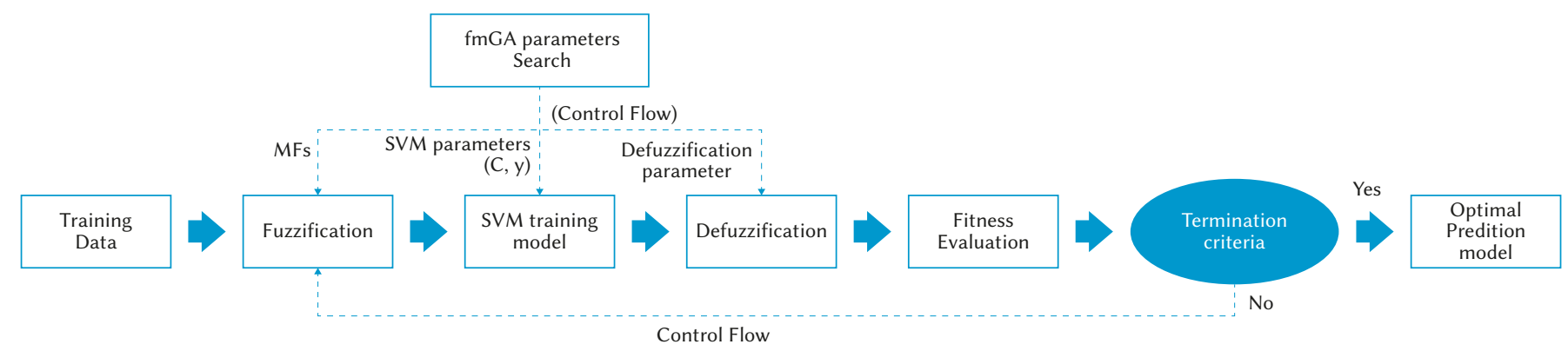

Fig. 12. Architecture of EFSIM [31].

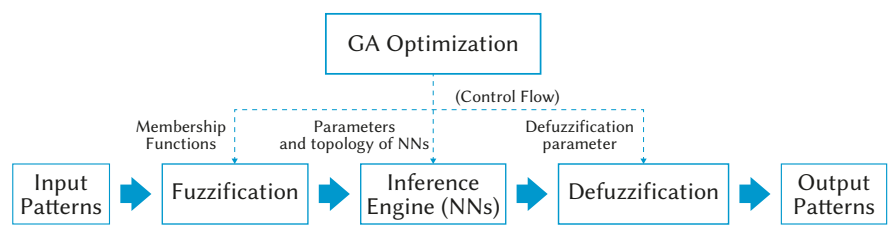

Fig. 13. EFNIM Architecture [26].

\section{Evolutionary Diffuse Hybrid Neuronal Network (EFHNN)}

The EFHNN mechanism is a fusion of HNN, FL, GA, and HNN. The advantage this system has over EFNIM is that the former is capable of handling deeper problems due to the large number of HNN models.

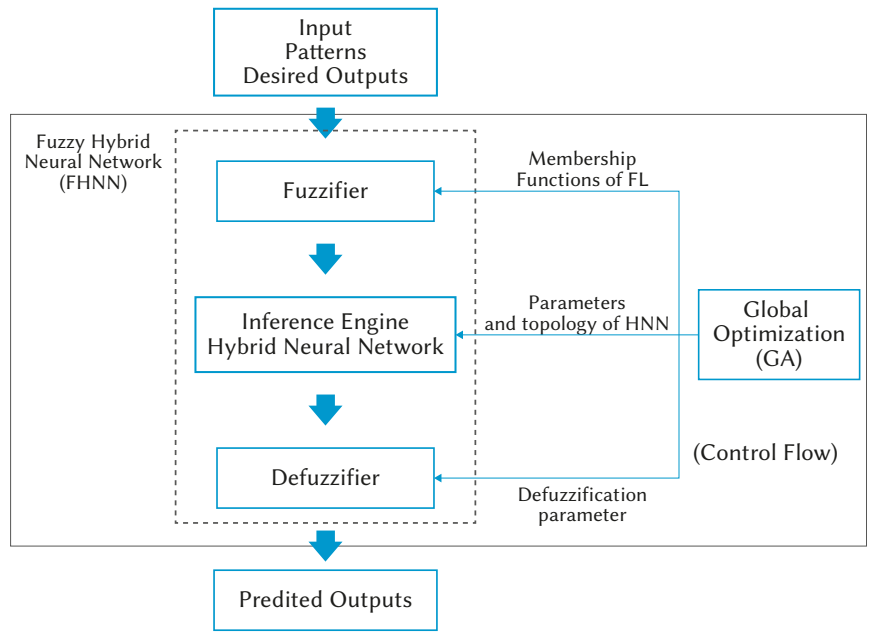

Fig. 14. EFHNN Architecture [29].

As noted, the proposed EFHNN for project management incorporates four AI approaches: NN, HONN, FL, and GA, as shown in Fig. 14. Here, the NN and HONN are composed of the inference engine, that is, the proposed HNN, the FL masters the fuzzifier and defuzzifier layers, and the GA optimizes the HNN and FL. Currently, there exist a small number of works that focus on this system in relation to project management in the field of civil engineering [32].

\section{Other Relevant Optimization Techniques}

Within the broad area of hybrid optimization techniques, there are a number that are worth mentioning. This includes firefly colony algorithm-based support vector regression (SAFCA-SVR) [37] and the fuzzy AHP and regression-based model [38]. Within the category of hybrid systems based on neural networks, there are a number of interesting examples, including multi-layer perceptron (MLP) combined with radial basis function network (RBFN) [77], diffuse object-oriented neural systems (OO-EFNIS) [92], wavelet-bootstrapANN (WBANN) [150], and neural networks combined with GA [113].

\section{Applications of Artificial Intelligence in Project} MANAGEMENT

In the next section, we provide a brief description of the main studies that are being carried out in the field of $\mathrm{AI}$ in relation to project management. The table 1 is also provided, which presents the main authors working in each field along with the optimization techniques used in each study.

\section{A. Tenders}

Tenders and technical offers that comprise the first phase of the project, wherein the initial estimates and designs are proposed in order to ascertain how much the project will cost as well as its scope. While the area is perhaps underexplored, there exist a number of interesting studies [38] on bidding strategies to support the decision making or AI models optimized to predict the project award price. In one study, the proposed model was used to analyze the data on bridge construction projects taken from the database of the Taiwan Public Construction Commission. The bid evaluation model and the cost probability curve model can be used as a strategic tool to quantify the project risks and to calculate the bids and tenders for construction projects. Another study [148] focused on machine learning and AI in terms of their impact on personal selling and sales management, with the impact discussed in relation to a small area of sales and research practice based on the seven steps of the sales process. From this, the implications for theory and practice can be derived.

\section{B. Project Health}

A number of studies exist that focus on project management in relation to health. The studies are fairly diverse and include research [73] on achieving strategic control over the project's cash flows in order to develop appropriate strategies that apply factors such as the task execution time, the construction rate, and the demand for resources for cash-flow control. There are also a number of studies that analyze the project risks, with a model proposed [94] for risk analysis using the unrestricted automatic causality of data from various software projects. Here, it was demonstrated that the proposed model discovers the causalities according to expert knowledge. For the prediction of the timeframes in the management of construction projects [82], researchers have proposed the application of AI instruments within the construction schedule [14]. In this study, an original optimization dispersion search algorithm was presented, which takes into account both the technological and the organizational constraints.

\section{Human Resources}

Within the field of project management, human resource management is crucial since the projects depend on having the best possible human capital. One study [116] provided a new approach to the evaluation and classification of candidates during the recruitment process, which involves estimating their emotional intelligence using the data from social networks. Elsewhere, in [82], the focus was on efficient classification algorithms to predict employee performance 
TABLE I. Main Studies of EAch Research Area

\begin{tabular}{|c|c|c|}
\hline Category & Investigation & $\begin{array}{c}\text { Optimization Techniques } \\
\text { Used }\end{array}$ \\
\hline \multicolumn{3}{|c|}{ Tenders } \\
\hline $\begin{array}{l}\text { Predicting project award } \\
\text { price }\end{array}$ & [36] & $(\mathrm{NN})+(\mathrm{CBR})$ \\
\hline Sales Prediction & [148] & (SVM), (NN) \\
\hline \multicolumn{3}{|c|}{ Project } \\
\hline Project data analytics & $\begin{array}{c}{[28]} \\
{[7]}\end{array}$ & $\begin{array}{l}\text { (EFNIM) } \\
\text { (Bootstrap) }\end{array}$ \\
\hline $\begin{array}{c}\text { Project risk modeling, } \\
\text { mitigation and management }\end{array}$ & $\begin{array}{l}{[72]} \\
{[34]}\end{array}$ & $\begin{array}{c}(\mathrm{BN}),(\mathrm{BNCC}) \\
(\mathrm{GA})+(\mathrm{SVM})\end{array}$ \\
\hline $\begin{array}{l}\text { Project mitigation and } \\
\text { recovery plans }\end{array}$ & [93] & $(\mathrm{ANN})+(\mathrm{CBR})$ \\
\hline $\begin{array}{l}\text { Project execution discovery } \\
\text { and modeling }\end{array}$ & $\begin{array}{l}{[11]} \\
{[94]}\end{array}$ & $\begin{array}{c}(\mathrm{GA})+(\mathrm{CPM}) \\
(\mathrm{GA})+(\mathrm{FL})+(\mathrm{NN})=(\mathrm{EFNIM})\end{array}$ \\
\hline $\begin{array}{l}\text { Real time predictive } \\
\text { analytics }\end{array}$ & $\begin{array}{l}{[69]} \\
{[32]}\end{array}$ & $\begin{array}{c}(\mathrm{GA}) \\
(\mathrm{EFHNN})\end{array}$ \\
\hline Agile Project Management & [44] & $(\mathrm{CNN})$ \\
\hline $\begin{array}{l}\text { Automated report } \\
\text { generation }\end{array}$ & [45] & (GA) \\
\hline \multicolumn{3}{|c|}{ Human Resources } \\
\hline $\begin{array}{c}\text { Candidate identification and } \\
\text { screening }\end{array}$ & [116] & (DT), (SVM) and (BN). \\
\hline Performance management & [82] & (DT) \\
\hline Retention management & [78] & (DT) \\
\hline HR analytics & [140] & $(\mathrm{ANN})$ \\
\hline \multicolumn{3}{|c|}{ Information Technology } \\
\hline $\begin{array}{c}\text { Cybersecurity prediction } \\
\text { and analytics }\end{array}$ & $\begin{array}{l}{[149]} \\
{[133]}\end{array}$ & $\begin{array}{c}(\mathrm{ANN})+(\mathrm{BLN})+(\mathrm{SOM}) \\
(\mathrm{ANN}),(\mathrm{FL}),(\mathrm{DT}),(\mathrm{KNN}) \\
(\mathrm{SVM})\end{array}$ \\
\hline Knowledge management & [21] & $(\mathrm{ANN})+(\mathrm{FL})+(\mathrm{GA})$ \\
\hline Design recognition library & [114] & (GA) \\
\hline $\begin{array}{l}\text { Innovation support and } \\
\text { prioritization }\end{array}$ & [141] & $(\mathrm{ANN})+(\mathrm{FL})+(\mathrm{GA})$ \\
\hline \multicolumn{3}{|c|}{ Logistics } \\
\hline $\begin{array}{c}\text { Automated Logistical Truck } \\
\text { Services }\end{array}$ & [3] & (RNN), (CNN) \\
\hline $\begin{array}{c}\text { Object Detection and } \\
\text { Classification Avoidance and } \\
\text { Navigation }\end{array}$ & [15] & $\begin{array}{c}\text { (ACO), (AG) (ANN), (AS). } \\
\text { (AIS)- (FNN) }\end{array}$ \\
\hline
\end{tabular}

and on the mining that is commonly used in many areas and has been carried out by applying decision tree and classification algorithms for predicting employee performance.

\section{Information Technology}

Information technology is a new area within project management but is one that is as important as all the other processes. A study was carried out [149] in relation to an implementation model for computer and network security purposes. Here, the aim was to use the model to combat malicious user activity. A smart hybrid system based on Bayesian learning networks and self-organizing maps was created and used to classify the networks and the host-based data collected

\begin{tabular}{|c|c|c|}
\hline Category & Investigation & $\begin{array}{l}\text { Optimization Techniques } \\
\text { Used }\end{array}$ \\
\hline \multicolumn{3}{|c|}{ Engineering \& Design } \\
\hline Planning & $\begin{array}{c}{[6]} \\
{[105]} \\
{[118]} \\
\end{array}$ & $\begin{array}{c}(\mathrm{ANN}) \\
(\mathrm{GA})+(\mathrm{TS}) \\
(\mathrm{GA}) \\
\end{array}$ \\
\hline Stakeholder Management & [33] & (EFSIM) \\
\hline Estimating & $\begin{array}{l}{[80]} \\
{[107]}\end{array}$ & $\begin{array}{c}(\mathrm{MA}) \\
(\mathrm{ANN})+(\mathrm{FL})\end{array}$ \\
\hline $\begin{array}{c}\text { Design automation and } \\
\text { optimization }\end{array}$ & $\begin{array}{c}{[134]} \\
{[164]} \\
{[9]} \\
{[83]} \\
{[115]} \\
{[131]}\end{array}$ & $\begin{array}{c}(\mathrm{ANN})+(\mathrm{GA}) \\
(\mathrm{GA}),(\mathrm{PSO}),(\mathrm{SA}),(\mathrm{AIS}), \\
(\mathrm{HS}) \\
(\mathrm{ANN}) \\
(\mathrm{ANN}) \\
(\mathrm{ANN})+(\mathrm{GA}) \\
(\mathrm{PNN}) \\
\end{array}$ \\
\hline Generative design & {$[110]$} & $\begin{array}{c}(\mathrm{ANN}),(\mathrm{GA}),(\mathrm{BN}),(\mathrm{SVM}) \\
(\mathrm{HS})\end{array}$ \\
\hline Continuous improvement & [117] & (WOA) \\
\hline Evolving skills & {$[25]$} & $(\mathrm{wSVM})+(\mathrm{FL})+(\mathrm{fmGA})$ \\
\hline \multicolumn{3}{|c|}{ Operations } \\
\hline $\begin{array}{l}\text { Back office/ automation/ } \\
\text { Facilities management }\end{array}$ & [157] & (MLR), (ANN), (SVM), (HS) \\
\hline Predictive maintenance & $\begin{array}{l}{[156]} \\
{[106]}\end{array}$ & $\begin{array}{c}(\mathrm{ANN})+(\mathrm{FL})+(\mathrm{GA}) \\
(\mathrm{ANN})+(\mathrm{FL})+(\mathrm{GA})+(\mathrm{CBR})\end{array}$ \\
\hline Operating project analytics & {$[16]$} & $(\mathrm{ANN})+(\mathrm{FL})+(\mathrm{GA})$ \\
\hline Autonomous systems & {$[121]$} & $(\mathrm{ANN})+(\mathrm{FL})+(\mathrm{GA})+(\mathrm{PSO})$ \\
\hline \multicolumn{3}{|c|}{ Supply Chain } \\
\hline Supply Chain & {$[161]$} & $(\mathrm{ANN})$ \\
\hline \multicolumn{3}{|c|}{ Construction } \\
\hline Construction management & {$[76]$} & $(\mathrm{ANN})$ \\
\hline Construction cost estimation & $\begin{array}{r}{[89]} \\
{[88]} \\
{[139]} \\
\end{array}$ & $\begin{array}{c}(\mathrm{CBR})+(\mathrm{GA}) \\
(\mathrm{ANN})+(\mathrm{CBR})+(\mathrm{MRA}) \\
(\mathrm{MLP})+(\mathrm{GPA}) \\
\end{array}$ \\
\hline $\begin{array}{c}\text { Construction risk } \\
\text { management }\end{array}$ & [68] & (Bootstrap) \\
\hline $\begin{array}{c}\text { Construction contract } \\
\text { management }\end{array}$ & [39] & (CBR) \\
\hline Construction safety & {$[127]$} & (ANN) \\
\hline Project portfolio selection & $\begin{array}{c}{[1]} \\
{[138]}\end{array}$ & $\begin{array}{c}(\mathrm{CBR})+(\mathrm{FL}) \\
(\mathrm{HNN})+(\mathrm{PSO})\end{array}$ \\
\hline $\begin{array}{c}\text { Onsite supervisory } \\
\text { manpower/ } \\
\text { Management }\end{array}$ & $\begin{array}{l}{[23]} \\
{[22]}\end{array}$ & $\begin{array}{l}(\mathrm{ANN})+(\mathrm{CBR}) \\
(\mathrm{ANN})+(\mathrm{CBR})\end{array}$ \\
\hline
\end{tabular}

within a local area network. Elsewhere, a study on cybersecurity and the optimization in smart "autonomous" buildings [124] explored the opportunities and challenges related to cybersecurity in Internet of Things (EIoT) environments in terms of the energy in smart buildings. Here, the proposed model can make decisions based on the data from neural networks that are designed with a circuit feedback loop with the ability to learn over time, which allows for learning from defined datasets and making smart decisions.

\section{E. Engineering and Design}

AI methods have been used for the optimization of hybrid energy systems [164] and models (evolutionary diffuse SVM) for estimating 
the construction costs. It is essential to monitor the project costs and to identify any potential problems.

\section{F. Operations}

Operation and maintenance are also important aspects of industrial projects, and numerous studies show how AI affects future predictive maintenance. Here, one study [156] discusses the impact of AI on predictive maintenance, which is an important aspect of advanced production systems.

\section{G. Supply Chain}

A two-stage methodology has been applied to an industrial survey dataset to investigate the relationships between key factors in a supply chain model [161]. The advantage of this model is that it frees the researcher from making subjective decisions during the analysis in terms of, for example, specifying the acceptable initial route models required for standard analysis.

\section{H. Logistics}

Researchers have conducted a general analysis of the AI techniques applied throughout the world to address transportation issues, primarily in terms of traffic management, traffic safety, public transportation, and urban mobility [3]. Further studies on the management of warehouses using AI have also been conducted [15], while DHL also proposed an interesting approach in [62].

\section{Construction}

Neural networks are regarded as a promising management tool that can enhance the current automation efforts in project management [76], the construction phase, and the engineering phase [63]. Studies on AI have also been carried out to identify the security risks in construction, with a focus on the management of the portfolio of projects using AI while taking into account the factors that generate risk in industrial projects and the historical records of the company [1].

\section{CONCLUSIONS}

The possibility of project success is a field of research in which researchers are working intensively. Here, the initial approaches were based on statistical models that have not responded to the needs of project management. In the field of AI, researchers have identified the algorithms and tools that can best deal with the various project variables and complex environments, with specific algorithms devised to address specific problems in the project. The main conclusions drawn from the reviewed works include that AI tools are more precise than traditional tools, while, at present, they remain somewhat complementary to the traditional approaches.

AI tools are highly useful to the project manager in terms of controlling and monitoring the project; however, many of the reviewed models involve weaknesses and limitations, which indicates that project managers should continue to use their experience when making evaluations according to the results. The trend of merging different AI tools continues to hold sway, wherein the strengths of one tool can compensate for the weaknesses of another. Indeed, this approach is returning the best results, and this is where the future lies. In this work, we studied the available AI techniques and the possible applications in the field of project management. In future work, a hybrid computational model that could fully ascertain the potential of AI in the field of project management will be proposed. The hope is that the management of autonomous projects will only require the partial supervision of a human project manager.

However, an autonomous project management system will also need to consider and fully control the project environment, including in terms of the status of the customers or the project stakeholders. Such a system can be used to apply AI algorithms for psychological and emotional analysis to evaluate both team performance and customer satisfaction. Looking to the future of 25 years from now, it is likely that there will exist an AI capable of managing the entire project, albeit with some form of human supervision.

The slow progress of $\mathrm{AI}$ in the field of project management is largely due to the lack of investment from private companies, which means progress is only been made in the universities and the public research organizations. In the future, AI will make all the decisions and will manage the resources in an optimal and timely manner, while the project manager will take the role of data scientist, working as part of a team with the AI to interpret the data and the decision making. Overall then, project managers will continue to play a crucial role when the AI is fully developed.

\section{ACKNOWLEDGMENTS}

I wish to thank my thesis tutors for the great help they provided. I also thank my family, especially my father, Francisco Gil Moreno, a successful businessman, without whom I could not have got where I am today, may he rest in peace.

\section{REFERENCES}

[1] H. R. Abbasianjahromi and H. Rajaie, "Application of fuzzy cbr and modm approaches in the project portfolio selection in construction companies," Iranian Journal of Science and Technology - Transactions of Civil Engineering, vol. 37, no. C1, pp. 143-155, 2013.

[2] A. Y. Abdelaziz, M. Z. Kamh, S. F. Mekhamer, and M. A. L. Badr, "A hybrid HNN-QP approach for dynamic economic dispatch problem," Electric Power Systems Research., vol. 78, no. 10, pp. 1784-1788, 2008, doi: 10.1016/j.epsr.2008.03.011.

[3] R. Abduljabbar, H. Dia, S. Liyanage, and S. A. Bagloee, "Applications of artificial intelligence in transport: An overview," Sustainability (Switzerland), vol. 11, no. 1. 2019, doi: 10.3390/su11010189.

[4] A. Abraham, "Adaptation of Fuzzy Inference System Using Neural Learning, in Fuzzy Systems Engineering: Theory and Practice, Studies in Fuzziness and Soft Computing," Studies in Fuzziness and Soft Computing, vol. 181, no. 3, 2005 .

[5] B. Akay and D. Karaboga, "Artificial bee colony algorithm for large-scale problems and engineering design optimization," Journal of Intelligent Manufacturing, vol. 23, pp. 1001-1014, 2012, doi: 10.1007/s10845-0100393-4.

[6] F. Amer and M. Golparvar-Fard, "Formalizing Construction Sequencing Knowledge and Mining Company-Specific Best Practices from Past Project Schedules," in Computing in Civil Engineering 2019: Visualization, Information Modeling, and Simulation - Selected Papers from the ASCE International Conference on Computing in Civil Engineering 2019, 2019, pp. 215-223, doi: 10.1061/9780784482421.028.

[7] L. Angelis and I. Stamelos, "A simulation tool for efficient analogy based cost estimation," Empirical Software Engineering, vol. 5, no. 1, pp. 35-68, 2000, doi: 10.1023/A:1009897800559.

[8] D. Anguita, A. Ghio, N. Greco, L. Oneto, and S. Ridella, "Model selection for support vector machines: Advantages and disadvantages of the Machine Learning Theory," in Proceedings of the International Joint Conference on Neural Networks, 2010, doi: 10.1109/IJCNN.2010.5596450.

[9] O. Arslan and O. Yetik, "ANN based optimization of supercritical ORCBinary geothermal power plant: Simav case study," in Applied Thermal Engineering, 2011, vol. 31, no. 17-18, pp. 3922-3928, doi: 10.1016/j. applthermaleng.2011.07.041.

[10] L. Auria and R. A. Moro, "support vector machine as a Technique of Solvency analysis,” DIW Berlin, vol. 811, 2008. doi: 10.2139/ssrn.1424949.

[11] R. F. Aziz, S. M. Hafez, and Y. R. Abuel-Magd, "Smart optimization for mega construction projects using artificial intelligence," Alexandria Eng. J., vol. 53, no. 3, pp. 591-606, 2014, doi: 10.1016/j.aej.2014.05.003.

[12] R. Bhattacharyya, P. Kumar, and S. Kar, "Fuzzy R\&D portfolio selection of 
interdependent projects," Computers and Mathematics with Applications, vol. 62, no. 10, pp. 3857-3870, 2011, doi: 10.1016/j.camwa.2011.09.036.T.

[13] Bhoskar, O. K. Kulkarni, N. K. Kulkarni, S. L. Patekar, G. M. Kakandikar, and V. M. Nandedkar, "Genetic Algorithm and its Applications to Mechanical Engineering: A Review," in Materials Today: Proceedings, 2015, vol. 2, no. 4-5, pp. 2624-2630, doi: 10.1016/j.matpr.2015.07.219.

[14] W. Boejko, Z. Hejducki, and M. Wodecki, "Applying metaheuristic strategies in construction projects management," Journal of Civil Engineering and Management, vol. 18, no. 5, pp. 621-630, Oct. 2012, doi: 10.3846/13923730.2012.719837.

[15] E. Bottani, R. Montanari, M. Rinaldi, and G. Vignali, "Intelligent algorithms for warehouse management," Intelligent Systems Reference Library, vol. 87, pp. 645-667, 2015, doi: 10.1007/978-3-319-17906-3_25.

[16] G. Braswell, "Artificial Intelligence Comes of Age in Oil and Gas," Journal of Petroleum Technology, vol. 65, no. 01, pp. 50-57, 2013, doi: 10.2118/0113-0050-jpt.

[17] S. T. Buckland, A. C. Davison, and D. V. Hinkley, "Bootstrap Methods and Their Application," Biometrics, vol. 52, no. 2, p. 795, 1998, doi: $10.2307 / 3109789$.

[18] E. Carmona, "Tutorial sobre Maquinas de Vectores Soporte (SVM)." 2016. UNED, Consultada en http://www. ia. uned. es/ ejcarmona/ publicaciones/[2013-Carmona]\%20SVM.pdf (fecha de consulta 01-072017).

[19] A. Castillo, J.M, Cortes, C, Gonzalez, J., \& Benito, "Prospecting The Future with AI," Internacional Journal of Artificial Intelligence and Interactive Multimedia, vol. 1, no. 2, pp. 1-53, 2009

[20] C. Chapell and V. Vapnik, "Model selection for Support Vector Machines," in Advances in Neural Information Processing Systems, 2000, pp. 230236, doi: $10.5555 / 3009657.3009690$

[21] [1] S. S. Chaudhry, M. W. Varano, and L. Xu, "Systems research, genetic algorithms and information systems," Systems Research and Behavioral Science, 2000, doi: 10.1002/(sici)1099-1743(200003/04)17:2<149::aidsres $290>3.3 . c 0 ; 2-h$.

[22] J. H. Chen and S. C. Hsu, "Hybrid ANN-CBR model for disputed change orders in construction projects," Automation in Construction, 2007, doi: 10.1016/j.autcon.2007.03.003.

[23] J. H. Chen, L. R. Yang, W. H. Chen, and C. K. Chang, "Case-based allocation of onsite supervisory manpower for construction projects," Construction Management and Economics, 2008, doi: 10.1080/01446190802014778.

[24] M. Y. Cheng, J. S. Chou, A. F. V. Roy, and Y. W. Wu, "High-performance Concrete Compressive Strength Prediction using Time-Weighted Evolutionary Fuzzy Support Vector Machines Inference Model," Automation in Construction, 2012, doi: 10.1016/j.autcon.2012.07.004.

[25] M. Y. Cheng, N. D. Hoang, A. F. V. Roy, and Y. W. Wu, "A novel timedepended evolutionary fuzzy SVM inference model for estimating construction project at completion," Engineering Applications of Artificial Intelligence, vol. 25, no. 4, pp. 744-752, 2012, doi: 10.1016/j. engappai.2011.09.022.

[26] M. Y. Cheng, L. C. Lien, H. C. Tsai, and P. H. Chen, "Artificial intelligence approaches to dynamic project success assessment taxonomic," Life Science Journal, vol. 9, pp. 5156-5163, 2012.

[27] M. Y. Cheng, H. C. Tsai, and W. S. Hsieh, "Web-based conceptual cost estimates for construction projects using Evolutionary Fuzzy Neural Inference Model," Automation in Construction, vol. 18, no. 2, pp. 164-172, 2009, doi: 10.1016/j.autcon.2008.07.001.

[28] M. Y. Cheng, H. C. Tsai, and C. L. Liu, "Artificial intelligence approaches to achieve strategic control over project cash flows," Automation in Construction, vol. 18, no. 4, pp. 386-393, 2009, doi: 10.1016/j. autcon.2008.10.005.

[29] M. Y. Cheng, H. C. Tsai, and E. Sudjono, "Evaluating subcontractor performance using evolutionary fuzzy hybrid neural network," International Journal of Project Management, vol. 29, no. 3, pp. 349-356, 2011, doi: 10.1016/j.ijproman.2010.03.005.

[30] M. Y. Cheng, H. C. Tsai, and E. Sudjono, "Evolutionary fuzzy hybrid neural network for conceptual cost estimates in construction projects," in 2009 26th International Symposium on Automation and Robotics in Construction, ISARC 2009, 2009, pp. 512-519, doi: 10.22260/ isarc2009/0040.

[31] M. Y. Cheng, D. K. Wibowo, D. Prayogo, and A. F. V. Roy, "Predicting productivity loss caused by change orders using the evolutionary fuzzy support vector machine inference model,' Journal of Civil Engineering and Management, vol. 21, no. 7, pp. 881-892, Oct. 2015, doi: 10.3846/13923730.2014.893922.

[32] T. M. Cheng and R. Z. Yan, "Integrating messy genetic algorithms and simulation to optimize resource utilization," Computer-Aided Civil and Infrastructure Engineering, vol. 24, no. 6, pp. 401-415, 2009, doi: 10.1111/j.1467-8667.2008.00588.x.

[33] J. S. Chou, M. Y. Cheng, and Y. W. Wu, "Improving classification accuracy of project dispute resolution using hybrid artificial intelligence and support vector machine models," Expert Systems with Applications, vol. 40, no. 6, pp. 2263-2274, 2013, doi: 10.1016/j.eswa.2012.10.036.

[34] J. S. Chou, M. Y. Cheng, Y. W. Wu, and A. D. Pham, "Optimizing parameters of support vector machine using fast messy genetic algorithm for dispute classification," Expert Syst. Appl., 2014, doi: 10.1016/j.eswa.2013.12.035.

[35] J. S. Chou, M. Y. Cheng, Y. W. Wu, and A. D. Pham, "Optimizing parameters of support vector machine using fast messy genetic algorithm for dispute classification," Expert Systems with Applications, vol. 41, no. 8, pp. 3955-3964, 2014, doi: 10.1016/j.eswa.2013.12.035.

[36] J. S. Chou and A. D. Pham, "Smart Artificial Firefly Colony AlgorithmBased Support Vector Regression for Enhanced Forecasting in Civil Engineering," Computer-Aided Civil and Infrastructure Engineering, vol. 30, no. 9, pp. 715-732, 2015, doi: 10.1111/mice.12121.

[37] J. S. Chou and A. D. Pham, "Smart Artificial Firefly Colony AlgorithmBased Support Vector Regression for Enhanced Forecasting in Civil Engineering," Comput. Civ. Infrastruct. Eng., 2015, doi: 10.1111/ mice.12121.

[38] J. S. Chou, A. D. Pham, and H. Wang, "Bidding strategy to support decision-making by integrating fuzzy AHP and regression-based simulation," Automation in Construction, vol. 35, pp. 517-527, 2013, doi: 10.1016/j.autcon.2013.06.007.

[39] D. K. Chua and P. K. Loh, "CB-Contract: Case-Based Reasoning Approach to Construction Contract Strategy Formulation," Journal of Computing in Civil Engineering, vol. 20, no. 5, pp. 339-350, 2006, doi: 10.1061/ (asce)0887-3801(2006)20:5(339)

[40] O. Cordón, "A historical review of evolutionary learning methods for Mamdani-type fuzzy rule-based systems: Designing interpretable genetic fuzzy systems," International Journal of Approximate Reasoning, vol. 52, no. 6. pp. 894-913, 2011, doi: 10.1016/j.ijar.2011.03.004.

[41] F. Costantino, G. Di Gravio, and F. Nonino, "Project selection in project portfolio management: An artificial neural network model based on critical success factors," International Journal of Project Management, vol. 33, no. 8, pp. 1744-1754, 2015, doi: 10.1016/j.ijproman.2015.07.003.

[42] E. Cox, Fuzzy Modeling and Genetic Algorithms for Data Mining and Exploration. 2005. Doi: 10.1016/B978-0-12-194275-5.X5000-2.

[43] A. L. A. Dalhoum and M. Al-Rawi, "High-Order Neural Networks are Equivalent to Ordinary Neural Networks," Modern Applied Science, vol. 13, no. 2, p. 228, Jan. 2019, doi: 10.5539/mas.v13n2p228.

[44] H. K. Dam, T. Tran, J. Grundy, A. Ghose, and Y. Kamei, "Towards effective AI-powered agile project management," in Proceedings - 2019 IEEE/ACM 41st International Conference on Software Engineering: New Ideas and Emerging Results, ICSE-NIER 2019, 2019, pp. 41-44, doi: 10.1109/ICSENIER.2019.00019.

[45] R. Day, J. Zydallis, G. Lamont, and R. Pachter, "Analysis of fine granularity and building block sizes in the parallel fast messy GA," in Proceedings of the 2002 Congress on Evolutionary Computation, CEC 2002, 2002, vol. 1, pp. 127-132, doi: 10.1109/CEC.2002.1006221.

[46] J. J. G. De la Rosa, A. A. Pérez, J. C. Palomares Salas, J. G. Ramiro Leo, and A. M. Muñoz, "A novel inference method for local wind conditions using genetic fuzzy systems," Renewable Energy, vol. 36, no. 6, pp. 1747-1753, 2011, doi: 10.1016/j.renene.2010.12.017.

[47] N. Dong, M. Fischer, D. Ge, and R. E. Levitt, "Automated look-ahead schedule generation and optimization for the finishing phase of complex construction projects," CIFE Technical Report, Stanford University, no. June, p. 1 online resource., 2012.

[48] S. Ebrahimnejad, S. M. Mousavi, and H. Seyrafianpour, "Risk identification and assessment for build-operate-transfer projects: A fuzzy multi attribute decision making model," Expert Systems with Applications, vol. 37, no. 1, pp. 575-586, Jan. 2010, doi: 10.1016/j.eswa.2009.05.037.

[49] T. Efendigil, S. Önüt, and C. Kahraman, "A decision support system for demand forecasting with artificial neural networks and neuro-fuzzy 
models: A comparative analysis," Expert Systems with Applications, vol. 36, no. 3 PART 2, pp. 6697-6707, 2009, doi: 10.1016/j.eswa.2008.08.058.

[50] B. Efron and R. Tibshirani, "Bootstrap methods for standard errors, confidence intervals, and other measures of statistical accuracy," Statistical Science, vol. 1, no. 1, pp. 54-75, 1986, doi: 10.1214/ss/1177013815.

[51] C. Egbu and S. Suresh, "Knowledge Mapping Techniques Within The Construction Industry:An Exploratory Study," CIB W102-Information Knowl. Manag. Build., pp. 48-57, 2008.

[52] C. Egbu and S. Suresh, "Knowledge Mapping Techniques Within The Construction Industry:An Exploratory Study," CIB W102-Information and knowledge management in Buildings, pp. 48-57, 2008.

[53] A. O. Esogbue and J. A. Murrell, "Fuzzy adaptive controller using reinforcement learning neural networks," in 1993 IEEE International Conference on Fuzzy Systems, 1993, pp. 178-183, doi: 10.1109/ fuzzy.1993.327494.

[54] W. H. Estler H.C, "Heuristic Search-Based Planning for Graph Transformation Systems," ICAPS Workshop on Knowledge Engineering for Planning and Scheduling, p. 54, 2011.

[55] A. M. Fahim, A. M. Salem, F. A. Torkey, and M. A. Ramadan, "Efficient enhanced k-means clustering algorithm," Journal of Zhejiang University: Science, vol. 7, no. 10, pp. 1626-1633, 2006, doi: 10.1631/jzus.2006.A1626.

[56] E. Faliagka et al., "On-line consistent ranking on e-recruitment: Seeking the truth behind a well-formed CV," Artificial Intelligence Review, vol. 42, no. 3, pp. 515-528, 2014, doi: 10.1007/s10462-013-9414-y.

[57] M. Fazzolari, R. Alcala, Y. Nojima, H. Ishibuchi, and F. Herrera, "A review of the application of multiobjective evolutionary fuzzy systems: Current status and further directions," IEEE Transactions on Fuzzy Systems, vol. 21, no. 1, pp. 45-65, 2013, doi: 10.1109/TFUZZ.2012.2201338.

[58] C. M. Fonseca and P. J. Fleming, "Genetic Algorithms for Multiobjective Optimization: Formulation, Discussion and Generalization," Icga, vol. 93, no. July, pp. 416-423, 1993, doi: citeulike-article-id:2361311.

[59] A. Fukunaga, G. Rabideau, S. Chien, and D. Yan, "Towards an application framework for automated planning and scheduling," in IEEE Aerospace Applications Conference Proceedings, 1997, vol. 1, pp. 375-386, doi: 10.1109/aero.1997.574426.

[60] T. Ganesan, P. Vasant, and I. Elamvazuthi, "Hopfield neural networks approach for design optimization of hybrid power systems with multiple renewable energy sources in a fuzzy environment," Journal of Intelligent and Fuzzy Systems, vol. 26, no. 5, pp. 2143-2154, 2014, doi: 10.3233/IFS130889.

[61] B. S. Garcia, R., Perez, I., Villavicencio, N., Piñero, P., "Experiences by using genetic algorithms in project scheduling," Revista Cubana de Ciencias Informáticas, vol. 10, pp. 71-86, 2016.

[62] L. Kota, "Artificial Intelligence in Logistics," Advanced Logistic Systems - Theory and Practice, vol. 12, no. 1, pp. 47-60, 2019, doi: 10.32971/ als.2019.004.

[63] Y. M. Goh and D. K. H. Chua, "Case-Based Reasoning Approach to Construction Safety Hazard Identification: Adaptation and Utilization," Journal of Construction Engineering and Management, vol. 136, no. 2, pp. 170-178, 2010, doi: 10.1061/(asce)co.1943-7862.0000116.

[64] D. Goldberg and K. Deb, "Rapid, accurate optimization of difficult problems using messy genetic algorithms," proceedings of the fifth international conference on genetic algorithms, pp. 56-64, 1993.

[65] D. GOLDBERG, "Messy Genetic Algorithms: Motivation, Analysis, and First Results," Complex Systems, vol. 3, no. 5, pp. 493-530, 1989.

[66] F. Hartman and R. A. Ashrafi, "Project Management in the Information Systems and Information Technologies Industries," Project Management Journal, 2002, doi: 10.1177/875697280203300303.

[67] H. Hashemi, S. M. Mousavi, and S. M. H. Mojtahedi, "Bootstrap technique for risk analysis with interval numbers in bridge construction projects," J. Constr. Eng. Manag., 2011, doi: 10.1061/(ASCE)CO.1943-7862.0000344.

[68] H. Hashemi, S. M. Mousavi, R. Tavakkoli-Moghaddam, and Y. Gholipour, "Compromise Ranking Approach with Bootstrap Confidence Intervals for Risk Assessment in Port Management Projects," Journal of Management in Engineering, vol. 29, no. 4, pp. 334-344, 2013, doi: 10.1061/(asce) me.1943-5479.0000167.

[69] T. Hegazy, "Optimization of construction time - Cost trade-off analysis using genetic algorithms," Canadian Journal of Civil Engineering, vol. 26, no. 6, pp. 685-697, 1999, doi: 10.1139/199-031.

[70] D. Heiss-Czedik, "An Introduction to Genetic Algorithms.," Artificial Life, vol. 3, no. 1, pp. 63-65, 1997, doi: 10.1162/artl.1997.3.63.

[71] F. Herrera, "Genetic fuzzy systems: Taxonomy, current research trends and prospects," Evolutionary Intelligence, vol. 1, no. 1, pp. 27-46, 2008, doi: 10.1007/s12065-007-0001-5.

[72] X. Hu, B. Xia, M. Skitmore, and Q. Chen, "The application of casebased reasoning in construction management research: An overview," Automation in Construction, vol. 72. pp. 65-74, 2016, doi: 10.1016/j. autcon.2016.08.023.

[73] Y. Hu, X. Zhang, E. W. T. Ngai, R. Cai, and M. Liu, "Software project risk analysis using Bayesian networks with causality constraints," Decision Support Systems, vol. 56, no. 1, pp. 439-449, Dec. 2013, doi: 10.1016/j. dss.2012.11.001.

[74] S. V. Ioannou, A. T. Raouzaiou, V. A. Tzouvaras, T. P. Mailis, K. C. Karpouzis, and S. D. Kollias, "Emotion recognition through facial expression analysis based on a neurofuzzy network," Neural Networks, vol. 18, no. 4, pp. 423-435, 2005, doi: 10.1016/j.neunet.2005.03.004.

[75] H. Ishibuchi, "Genetic fuzzy systems: evolutionary tuning and learning of fuzzy knowledge bases," Fuzzy Sets and Systems, vol. 141, no. 1, pp. 161-162, 2004, doi: 10.1016/s0165-0114(03)00262-8.

[76] M. Jain and K. K. Pathak, "Applications of artificial neural network in construction engineering and management - A review," International Journal of Engineering Technology, Management and Applied Sciences, vol. 2, no. 3, pp. 134-142, 2014.

[77] H. R. Jantan, A. A. Hamdan, and Z. Othman, "Human Talent Forecasting using Data Mining Classification Techniques," International Journal of Technology Diffusion, vol. 1, no. 4, pp. 29-41, 2011, doi: 10.4018/ jtd.2010100103.

[78] H. Jantan, "Human Talent Prediction in HRM using C4 . 5 Classification Algorithm," International Journal on Computer Science and Engineering, vol. 02 , no. 08 , pp. 2526-2534, 2010.

[79] C. D. Jeffries, "Tracking, code recognition, and memory management with high-order neural networks",Applications and Science of Artificial Neural Networks, 1995, vol. 2492, pp. 964-973, doi: 10.1117/12.205207.

[80] L. Jin, C. Zhang, X. Shao, and G. Tian, "Mathematical modeling and a memetic algorithm for the integration of process planning and scheduling considering uncertain processing times," Proceedings of the Institution of Mechanical Engineers, Part B: Journal of Engineering Manufacture, vol. 230, no. 7, pp. 1272-1283, 2016, doi: 10.1177/0954405415625916.

[81] V. Kachitvichyanukul, "Comparison of Three Evolutionary Algorithms: GA, PSO, and DE," Industrial Engineering and Management Systems, vol. 11, no. 3, pp. 215-223, 2012, doi: 10.7232/iems.2012.11.3.215.

[82] V. Kalaivani and M. M. Elamparithi, "An Efficient Classification Algorithms for Employee Performance Prediction," International Journal of Research in Advent Technology, vol. 2, no. 9, pp. 27-32, 2014.

[83] S. A. Kalogirou, "Artificial neural networks and genetic algorithms for the optimisation of solar thermal systems," in Artificial Intelligence in Energy and Renewable Energy Systems, Nova Science Publishers, Inc., 2006, pp. 131-162.

[84] T. Kanungo, D. M. Mount, N. S. Netanyahu, C. D. Piatko, R. Silverman, and $\mathrm{A}$. Y. Wu, "An efficient k-means clustering algorithms: Analysis and implementation," IEEE Transactions on Pattern Analysis and Machine Intelligence, vol. 24, no. 7, pp. 881-892, 2002, doi: 10.1109/ TPAMI.2002.1017616.

[85] S. Kar, S. Das, and P. K. Ghosh, "Applications of neuro fuzzy systems: A brief review and future outline," Applied Soft Computing Journal, vol. 15. pp. 243-259, 2014, doi: 10.1016/j.asoc.2013.10.014.

[86] H. Kargupta, "SEARCH, polynomial complexity, and the fast messy genetic algorithm," Urbana, vol. 51, no. 95008, p. 188, 1996.

[87] N. A. Kartam, R. E. Levitt, and D. E. Wilkins, "Extending Artificial Intelligence Techniques for Hierarchical Planning," Journal of Computing in Civil Engineering, vol. 5, no. 4, pp. 464-477, 1991, doi: 10.1061/ (asce)0887-3801(1991)5:4(464).

[88] G. H. Kim, S. H. An, and K. I. Kang, "Comparison of construction cost estimating models based on regression analysis, neural networks, and case-based reasoning," Build. Environ., 2004, doi: 10.1016/j. buildenv.2004.02.013.

[89] G. H. Kim, S. H. An, and K. I. Kang, "Comparison of construction cost estimating models based on regression analysis, neural networks, and case-based reasoning," Building and Environment, vol. 39, no. 10, pp. 1235-1242, 2004, doi: 10.1016/j.buildenv.2004.02.013. 
[90] O. Kisi, "Modeling solar radiation of Mediterranean region in Turkey by using fuzzy genetic approach," Energy, vol. 64, pp. 429-436, 2014, doi: 10.1016/j.energy.2013.10.009.

[91] M. Klumpp, "Automation and artificial intelligence in business logistics systems: human reactions and collaboration requirements," International Journal of Logistics Research and Applications, vol. 21, no. 3, pp. 224-242, 2018, doi: 10.1080/13675567.2017.1384451.

[92] C. H. Ko and M. Y. Cheng, "Hybrid use of AI techniques in developing construction management tools," Automation in Construction, vol. 12, no. 3, pp. 271-281, May 2003, doi: 10.1016/S0926-5805(02)00091-2.

[93] C.-H. Ko and M.-Y. Cheng, "Dynamic Prediction of Project Success Using Artificial Intelligence," Journal of Construction Engineering and Management, vol. 133, no. 4, pp. 316-324, 2007, doi: 10.1061/(asce)07339364(2007)133:4(316).

[94] C. H. Ko, M. Y. Cheng, and T. K. Wu, "Evaluating sub-contractors performance using EFNIM," Automation in Construction, vol. 16, no. 4, pp. 525-530, 2007, doi: 10.1016/j.autcon.2006.09.005.

[95] K. A. H. Kobbacy, "Application of Artificial Intelligence in maintenance modelling and management," in IFAC Proceedings Volumes (IFACPapersOnline), 2012, doi: 10.3182/20121122-2-ES-4026.00046.

[96] K. A. H. Kobbacy, "Application of Artificial Intelligence in maintenance modelling and management," in IFAC Proceedings Volumes (IFACPapersOnline), 2012, vol. 45, no. 31, pp. 54-59, doi: 10.3182/20121122-2ES-4026.00046.

[97] M. Kumar, M. Husain, N. Upreti, and D. Gupta, "Genetic Algorithm: Review and Application," SSRN Electronic Journal, vol. 2, no. 2, pp. 451454, 2020, doi: 10.2139/ssrn.3529843.

[98] H. K. Kwan, "High-order feedbackward neural networks," 1991, pp. 4951, doi: 10.1109/ciccas.1991.184277.

[99] H. Kwasnicka and M. Przewozniczek, "Multi population pattern searching algorithm: A new evolutionary method based on the idea of messy genetic algorithm," IEEE Trans. Evol. Comput., 2011, doi: 10.1109/ TEVC.2010.2102038.

[100] M. Lahmann, "AI will transform project management. Are you ready?," Pwc Switzerland, 2018. [Online]. Available: https://www.pwc.ch/en/ insights/risk/transformation-assurance-ai-will-transform-projectmanagement-are-you-ready.html.

[101] M. Laumanns and J. Ocenasek, "Bayesian optimization algorithms for multi-objective optimization," in Lecture Notes in Computer Science (including subseries Lecture Notes in Artificial Intelligence and Lecture Notes in Bioinformatics), 2002, vol. 2439, pp. 298-307, doi: 10.1007/3-54045712-7_29.

[102] G. G. Lendaris, K. Mathia, and R. Saeks, "Linear Hopfield networks and constrained optimization," IEEE Transactions on Systems, Man, and Cybernetics, Part B: Cybernetics, vol. 29, no. 1, pp. 114-118, 1999, doi: 10.1109/3477.740171.

[103] F. L. Lewis and D. Vrabie, "Reinforcement learning and adaptive dynamic programming for feedback control," IEEE Circuits and Systems Magazine, vol. 9, no. 3, pp. 32-50, 2009, doi: 10.1109/MCAS.2009.933854.

[104] M. Y. Leyva Vázquez, K. Pérez Teruel, A. Febles Estrada, and J. Gulín González, "Mapas cognitivos difusos para la selección de proyectos de tecnologías de la información," Contaduría y Administración, vol. 58, no. 4, pp. 95-117, 2013, doi: 10.1016/s0186-1042(13)71235-x.

[105] X. Li, L. Gao, and W. Li, "Application of game theory based hybrid algorithm for multi-objective integrated process planning and scheduling," Expert Systems with Applications, vol. 39, no. 1, pp. 288297, 2012, doi: 10.1016/j.eswa.2011.07.019.

[106] Z. Li, Y. Wang, and K. S. Wang, "Intelligent predictive maintenance for fault diagnosis and prognosis in machine centers: Industry 4.0 scenario," Advances in Manufacturing, vol. 5, no. 4, pp. 377-387, 2017, doi: 10.1007/ s40436-017-0203-8.

[107] R. . Lozada, "Redes neuronales y logica difusa aplicado a un sistema climatológico," Universidad nacional de San Agustin, 2017.

[108] P. C. K. Luk, K. C. Low, and A. Sayiah, "GA-based fuzzy logic control of a solar power plant using distributed collector fields," Renewable Energy, vol. 16, no. 1-4, pp. 765-768, 1999, doi: 10.1016/s0960-1481(98)00275-4.

[109] M. M. Mijwil, "Artificial Neural Networks Advantages and Disadvantages," Linkedin, no. March, 2018.

[110] V. Machairas, A. Tsangrassoulis, and K. Axarli, "Algorithms for optimization of building design: A review," Renewable and Sustainable
Energy Reviews, vol. 31. pp. 101-112, 2014, doi: 10.1016/j.rser.2013.11.036. [111] J. G. MacKinnon, "Bootstrap methods in econometrics," in Economic Record, 2006, vol. 82, no. SPEC. ISS. 1, doi: 10.1111/j.14754932.2006.00328.x.

[112] D. Magaña Martínez and J. C. Fernandez-Rodriguez, "Artificial Intelligence Applied to Project Success: A Literature Review," International Journal of Interactive Multimedia and Artificial Intelligence, vol. 3, no. 5, p. 77, 2015, doi: 10.9781/ijimai.2015.3510.

[113] R. Mahajan and G. Kaur, "Neural Networks using Genetic Algorithms," International Journal of Computer Applications, vol. 77, no. 14, pp. 6-11, Sep. 2013, doi: 10.5120/13549-1153.

[114] M. G. Marchetta and R. Q. Forradellas, "An artificial intelligence planning approach to manufacturing feature recognition," CAD Computer Aided Design, vol. 42, no. 3, pp. 248-256, 2010, doi: 10.1016/j.cad.2009.11.007.

[115] A. Mellit, S. a Kalogirou, and M. Drif, "Application of neural networks and genetic algorithms for sizing of photovoltaic systems," Renewable Energy, vol. 35, no. 12, pp. 2881-2893, 2010, doi: 10.1016/j.renene.2010.04.017.

[116] V. M. Menon and H. A. Rahulnath, "A novel approach to evaluate and rank candidates in a recruitment process by estimating emotional intelligence through social media data," in 2016 International Conference on Next Generation Intelligent Systems, ICNGIS 2016, 2017, doi: 10.1109/ ICNGIS.2016.7854061.

[117] S. Mirjalili and A. Lewis, "The Whale Optimization Algorithm," Advances in Engineering Software, vol. 95, pp. 51-67, 2016, doi: 10.1016/j. advengsoft.2016.01.008.

[118] J. R. Montoya-Torres, E. Gutierrez-Franco, and C. Pirachicán-Mayorga, "Project scheduling with limited resources using a genetic algorithm," International Journal of Project Management, vol. 28, no. 6, pp. 619-628, 2010, doi: 10.1016/j.ijproman.2009.10.003.

[119] A. Moreno and T. Redondo, "Text Analytics: the convergence of Big Data and Artificial Intelligence," International Journal of Interactive Multimedia and Artificial Intelligence, vol. 3, no. 6, p. 57, 2016, doi: 10.9781/ijimai.2016.369.

[120] O. Moselhi, T. Hegazy, and P. Fazio, "Neural Networks as Tools in Construction," Journal of Construction Engineering and Management, vol. 117, no. 4, pp. 606-625, 1991, doi: 10.1061/(asce)07339364(1991)117:4(606).

[121] G. P. Moustris, S. C. Hiridis, K. M. Deliparaschos, and K. M. Konstantinidis, "Evolution of autonomous and semi-autonomous robotic surgical systems: A review of the literature," International Journal of Medical Robotics and Computer Assisted Surgery, vol. 7, no. 4. pp. 375-392, 2011, doi: $10.1002 /$ rcs. 408 .

[122] K. N. Mutter, Z. M. Jafri, and A. A. Aziz, "Hopfield Neural Network (HNN) Improvement for color image recognition using multi-bitplane and multiconnect architecture," in Computer Graphics, Imaging and Visualisation: New Advances, CGIV 2007, 2007, pp. 403-407, doi: 10.1109/CGIV.2007.24.

[123] M. Mylrea and N. G. Gourisetti, "Cybersecurity and optimization in smart 'autonomous' buildings," in Autonomy and Artificial Intelligence: A Threat or Savior?, 2017, pp. 263-294.

[124] G. Napoles, "Algoritmo para mejorar la convergencia en Mapas Cognitivos Difusos Sigmoidales," Universidad Central "Marta Abreu” de Las Villas Facultad de Matemática, Física y Computación., 2014.

[125] D. Nau, S. Gupta, and W. Regli, "Manufacturing-Operation Planning Versus AI Planning," in AAAI Spring Symposium on Integrated Planning Applications, 1995.

[126] M. Obayashi, T. Nishida, T. Kuremoto, K. Kobayashi, and L. B. Feng, "A reinforcement learning system embedded agent with neural networkbased multi-valued pattern memory structure," in ICCAS 2010 International Conference on Control, Automation and Systems, 2010, pp. 176-181, doi: 10.1109/iccas.2010.5669888.

[127] D. A. Patel and K. N. Jha, "Neural Network Model for the Prediction of Safe Work Behavior in Construction Projects," Journal of Construction Engineering and Management, vol. 141, no. 1, p. 04014066, 2015, doi: 10.1061/(asce)co.1943-7862.0000922.

[128] M. Pelikan, D. E. Goldberg, and E. Cantú-Paz, "BOA : The Bayesian Optimization Algorithm 1 Introduction," Proceedings of the genetic and evolutionary computation conference GECCO-99, vol. 1, pp. 525-532, 1999.

[129] T. Pfeufer and M. Ayoubi, "Application of a hybrid neuro-fuzzy system to the fault diagnosis of an automotive electromechanical actuator," Fuzzy 
Sets and Systems, vol. 89, no. 3, pp. 351-360, 1997, doi: 10.1016/S01650114(97)00022-5.

[130] PMI, PMBOK Guide | Project Management Institute. 2017.

[131] S. M. Pourkiaei, M. H. Ahmadi, and S. M. Hasheminejad, "Modeling and experimental verification of a $25 \mathrm{~W}$ fabricated PEM fuel cell by parametric and GMDH-type neural network," Mech. Ind., 2016, doi: $10.1051 / \mathrm{meca} / 2015050$.

[132] R. Prieto, "Impacts of Artificial Intelligence on Management of Large Complex Projects," PM World Journal, vol. 8, no. 5, pp. 1-20, 2019.

[133] A. Rehman and T. Saba, "Evaluation of artificial intelligent techniques to secure information in enterprises," Artificial Intelligence Review, vol. 42, no. 4, pp. 1029-1044, 2014, doi: 10.1007/s10462-012-9372-9.

[134] C. Renzi, F. Leali, M. Cavazzuti, and A. O. Andrisano, "A review on artificial intelligence applications to the optimal design of dedicated and reconfigurable manufacturing systems," International Journal of Advanced Manufacturing Technology, vol. 72, no. 1-4, pp. 403-418, 2014, doi: 10.1007/s00170-014-5674-1.

[135] L. Ricalde, B. Cruz, and E. Sánchez, "Control neuronal recurrente de alto orden para turbinas de viento con generador síncrono de imán permanente," Computación y Sistemas, vol. 14, no. 2, pp. 133-143, 2010.

[136] L. Rodriguez-Repiso, R. Setchi, and J. L. Salmeron, "Modelling IT projects success with Fuzzy Cognitive Maps," Expert Systems with Applications, vol. 32, no. 2, pp. 543-559, 2007, doi: 10.1016/j.eswa.2006.01.032.

[137] L. Rutkowski, K. Cpałka, R. Nowicki, A. Pokropińska, and R. Scherer, "Neuro-fuzzy systems," in Computational Complexity: Theory, Techniques, and Applications, vol. 9781461418, 2012, pp. 2069-2081.

[138] A. N. Sadigh, H. Mokhtari, M. Iranpoor, and S. M. T. Fatemi Ghomi, "Cardinality constrained portfolio optimization using a hybrid approach based on particle swarm optimization and hopfield neural network," Advanced Science Letters, vol. 17, no. 1, pp. 11-20, 2012, doi: 10.1166/ asl.2012.3666.

[139] E. L. O. Savaş Bayram, Mehmet Emin Öcal, "Analysis of Cost and Schedule Variances in Construction Works with Artificial Intelligence Approaches: The Case of Turkey," in International Students' Conference of Civil Engineering, ISCCE, 2012, pp. 10-11.

[140] T. Schmitt, P. Caillou, and M. Sebag, "Matching Jobs and Resumes: a Deep Collaborative Filtering Task," 2018, vol. 41, pp. 124-109, doi: 10.29007/17rz.

[141] S. G. Selivanov, S. N. Poezjalova, and O. A. Gavrilova, "The Use of Artificial Intelligence Methods of Technological Preparation of EngineBuilding Production," American Journal of Industrial Engineering, vol. 2, no. 1, pp. 10-14, 2014, doi: 10.12691/AJIE-2-1-3.R.

[142] R. Sonmez, "Parametric Range Estimating of Building Costs Using Regression Models and Bootstrap," Journal of Construction Engineering and Management, vol. 134, no. 12, pp. 1011-1016, 2008, doi: 10.1061/ (asce)0733-9364(2008)134:12(1011).

[143] C. D. Stylios and P. P. Groumpos, "Modeling Complex Systems Using Fuzzy Cognitive Maps," IEEE Transactions on Systems, Man, and Cybernetics Part A:Systems and Humans., vol. 34, no. 1, pp. 155-162, 2004, doi: 10.1109/TSMCA.2003.818878.

[144] L. Suganthi, S. Iniyan, and A. A. Samuel, "Applications of fuzzy logic in renewable energy systems - A review," Renewable and Sustainable Energy Reviews, vol. 48. pp. 585-607, 2015, doi: 10.1016/j.rser.2015.04.037.

[145] M. Sugeno and T. Yasukawa, "A Fuzzy-Logic-Based Approach to Qualitative Modeling," IEEE Transactions on Fuzzy Systems, vol. 1, no. 1, pp. 7-31, 1993, doi: 10.1109/TFUZZ.1993.390281.

[146] H. K. Sulehria and Y. Zhang, "Hopfield Neural Networks - A Survey," Engineering, pp. 125-130, 2007.

[147] R. S. Sutton and A. G. Barto, "Reinforcement Learning: An Introduction," IEEE Transactions on Neural Networks, vol. 9, no. 5, pp. 1054-1054, Sep. 1998, doi: 10.1109/tnn.1998.712192.

[148] N. Syam and A. Sharma, "Waiting for a sales renaissance in the fourth industrial revolution: Machine learning and artificial intelligence in sales research and practice," Ind. Mark. Manag., vol. 69, pp. 135-146, 2018, doi: 10.1016/j.indmarman.2017.12.019.

[149] J. L. Thames, R. Abler, and A. Saad, "Hybrid intelligent systems for network security," in Proceedings of the Annual Southeast Conference, 2006, vol. 2006, pp. 286-289, doi: 10.1145/1185448.1185513.

[150] M. K. Tiwari and C. Chatterjee, "Development of an accurate and reliable hourly flood forecasting model using wavelet-bootstrap-ANN (WBANN) hybrid approach," Journal of Hydrology, vol. 394, no. 3-4, pp. 458-470, 2010, doi: 10.1016/j.jhydrol.2010.10.001

[151] M. K. Tiwari and C. Chatterjee, "Uncertainty assessment and ensemble flood forecasting using bootstrap based artificial neural networks (BANNs)," Journal of Hydrology, vol. 382, no. 1-4, pp. 20-33, 2010, doi: 10.1016/j.jhydrol.2009.12.013.

[152] A. Tsakonas and B. Gabrys, "A fuzzy evolutionary framework for combining ensembles," Applied Soft Computing Journal, vol. 13, no. 4, pp. 1800-1812, 2013, doi: 10.1016/j.asoc.2012.12.027.

[153] TutorialPoint.com, "Artificial Intelligence - Fuzzy Logic Systems." [Online]. Available: https://www.tutorialspoint.com/artificial_ intelligence/artificial_intelligence_fuzzy_logic_systems.htm.

[154] H. Umit, "Digital business strategies in blockchain ecosystems : transformational design and future of global business (E-book)," Contributions to Management Science, pp. 569-599, 2000.

[155] N. T. T. Vu, N. P. Tran, and N. H. Nguyen, "Adaptive neuro-fuzzy inference system based path planning for excavator arm," Journal of Robotics, vol. 2018, 2018, doi: 10.1155/2018/2571243.

[156] K. Wang and Y. Wang, "How AI Affects the Future Predictive Maintenance: A Primer of Deep Learning," in Lecture Notes in Electrical Engineering, 2018, doi: 10.1007/978-981-10-5768-7_1.

[157] Z. Wang and R. S. Srinivasan, "A review of artificial intelligence based building energy use prediction: Contrasting the capabilities of single and ensemble prediction models," Renewable and Sustainable Energy Reviews. 2017, doi: 10.1016/j.rser.2016.10.079.

[158] M. Wauters and M. Vanhoucke, "Support Vector Machine Regression for project control forecasting," Automation in Construction, vol. 47, pp. 92-106, 2014, doi: 10.1016/j.autcon.2014.07.014.

[159] R. Wehrens, H. Putter, and L. M. C. Buydens, "The bootstrap: A tutorial," Chemometrics and Intelligent Laboratory Systems, vol. 54, no. 1, pp. 35-52, 2000, doi: 10.1016/S0169-7439(00)00102-7.

[160] G. C. Whitley, D., Beveridge, J.R, GuerraSalcedo C., "Messy Genetic Algorithms for Subset Feature Selection," Department of Computer Science, pp. 568--575, 1997.

[161] T. C. Wong, K. M. Y. Law, H. K. Yau, and S. C. Ngan, "Analyzing supply chain operation models with the PC-algorithm and the neural network," Expert Systems with Applications, vol. 38, no. 6, pp. 7526-7534, 2011, doi: 10.1016/j.eswa.2010.12.115.

[162] J. A. Yacim and D. G. B. Boshoff, "Impact of artificial neural networks training algorithms on accurate prediction of property values," Journal of Real Estate Research, 2018.

[163] L. A. Zadeh, "Fuzzy sets," Information and Control, vol. 8, no. 3, pp. 338353, 1965, doi: 10.1016/S0019-9958(65)90241-X.

[164] S. M. Zahraee, M. Khalaji Assadi, and R. Saidur, "Application of Artificial Intelligence Methods for Hybrid Energy System Optimization," Renewable and Sustainable Energy Reviews, vol. 66. pp. 617-630, 2016, doi: 10.1016/j.rser.2016.08.028.

[165] G. Zhang, B. Eddy Patuwo, and M. Y. Hu, "Forecasting with artificial neural networks: The state of the art," International Journal of Forecasting, vol. 14, no. 1, pp. 35-62, 1998, doi: 10.1016/S0169-2070(97)00044-7.

[166] J. Zhang, "Developing robust non-linear models through bootstrap aggregated neural networks," Neurocomputing, vol. 25, no. 1-3, pp. 93113, 1999, doi: 10.1016/S0925-2312(99)00054-5. 


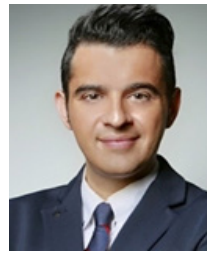

Jesús Gil Ruiz

Jesús Gil Ruiz is a PhD Candidate in computer science and is also an industrial engineer, civil engineer, and industrial organization engineer. He received an Msc Executive MBA, an Msc in Financial Management and Cost Control, and an Msc In Project, Construction, and Maintenance of Infrastructures and Facilities of Rail Lines from the University of Barcelona. Artificial Intelligence Program Applied to Strategic Management by MIT Management Executive Education and Business Analytics Program by Wharton Executive Education (University of Pennsylvania). He is a project manager in the renewable energy and oil and gas sectors, working in prestigious, internationally renowned companies such as TSK, Técnicas Reunidas, ABENGOA, and SENER Engineering and Systems. He has also participated in projects of great international importance, including BenBan Solar, the world's largest solar plant as of 2019 (1,800 MW), and Cauchari Solar (330MW), one of the largest photovoltaic plants built in Latin America in 2018. He is also an assistant professor at the University of La Rioja, where he works in the field of mathematics. He is also a trainer, lecturer, and speaker at Inicitivas Empresariales (an international company in Barcelona), working in the areas of project management, high-speed rail engineering and renewable energies.

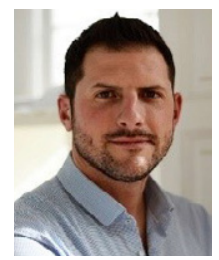

Javier Martínez Torres

Dr. Javier Martínez Torres is a Mathematician and Engineering $\mathrm{PhD}$ from the University of Vigo. He is currently an Assistant Professor at the University of Vigo and has participated in more than 20 research projects as principal investigator. He has published more than 50 papers in JCR indexed journals and participate in more than 25 international conferences.

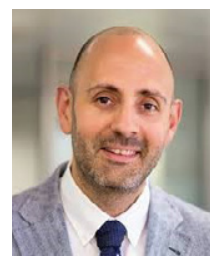

Rubén González Crespo

Dr. Rubén González Crespo has a $\mathrm{PhD}$ in Computer Science Engineering. Currently he is Vice Chancellor of Academic Affairs and Faculty from UNIR and Global Director of Engineering Schools from PROEDUCA Group. He is advisory board member for the Ministry of Education at Colombia and evaluator from the National Agency for Quality Evaluation and Accreditation of Spain (ANECA).

$\mathrm{He}$ is member from different committees at ISO Organization. Finally, He has published more than 200 papers in indexed journals and congresses. 